\title{
El culto a Tutela en la Asturias antigua
}

\section{INTRODUCCIÓN: EL CULTO A TUTELA EN SUELO HISPANO}

Hace ya más de tres décadas que se recopilaron los testimonios (básicamente epigráficos) correspondientes al culto de esta divinidad en las provincias hispanorromanas, así como el significado del mismo y las características sociales de los dedicantes de tales actividades religiosas ${ }^{1}$; en lo que respecta a este último punto Tutela parece haber contado, en el ámbito del Imperio romano, con abundantes adeptos entre los colectivos de libertos y esclavos, identificando sus funciones con las de un dios-guardián.

La problemática que se nos plantea, en primer término, arranca del hecho de que, desde tiempos de la dinastía de los Flavios, tomando como referente algunos modelos orientales, dicho culto adquiriría un carácter extraordinario, pasando a asimilarse a la Tyché o Fortuna oriental2 ${ }^{2}$; sin embargo, hemos de tener en cuenta que, desde los tiempos más remotos, existe en el panteón romano una Fortuna distinta de la Tyché griega, a lo que hemos de añadir el hecho de que esta divinidad no aparece asimilada únicamente a Fortuna sino también a Tutela y Genio $^{3}$ (para comprender el carácter de Tutela, tal vez tengamos que tratar de calibrar el grado de identificación existente en cada caso entre esta divinidad, la Fortuna y el Genio ${ }^{4}$ ).

Además de la documentación mencionada es posible que la inscripción que más se acerque al verdadero sentido de Tutela sea la consagrada al Genio civitatis $^{5}$; en este contexto no resulta frecuente la invocación a la Fortuna de un centro urbano, por lo que difícilmente podremos llegar a una asociación entre dicha divinidad y Tutela (hasta ahora no contamos con ningún resto epigráfico para testimoniarlo).

\footnotetext{
${ }^{1}$ M.J.Pena, «El culto a Tutela en Hispania», MHA 5 (1981) 73 ss.

2 G.del Cerro, «Reflexiones sobre la diosa Thykhe/ Fortuna», AMal 27 (2004) 143 ss.

${ }^{3}$ M.J.Pena, «El culto a Tutela en Hispania», p.73.

${ }^{4}$ CIL VI.126: Genio et Fortunae Tutelaeque huius loci; epígrafes nos 12, 13 y 14 de M.J.Pena «El culto a Tutela en Hispania», p.85: Genio Tutelae/ Tutelae Genio; CIL VI.178 = ILS 3722: deae Fortunae Tutelae...

${ }^{5}$ Equivalente al griego «tyché tês póleos» (A.E. 1965, $\left.\mathrm{n}^{\circ} 5\right)$. Cf. B.Goffaux, «Le culte au Génie de la cité dans la Péninsule Ibérique romaine», Pallas 66 (2004) 157 ss.
} 
Otra cuestión no menos importante se relaciona con el sexo de dicha divinidad: la iconografía de sus esculturas se vincula directamente a una mujer y así aparece reseñada en textos epigráficos correspondientes a otras regiones del Imperio romano ${ }^{6}$; frente a ello, en suelo hispano hallamos ejemplos en los que se consagran a Tutela varias inscripciones votivas en las que dicha divinidad aparece mencionada como deus (ver, entre otras, CIL II.4092 =ILS 5276 = Textos n ${ }^{\circ}$ 1, de Tarragona, en la actualidad desaparecida, o la de Mentesa Bastitanorum (La Guardia, Jaén) ${ }^{7}$ (es posible que tal indeterminación de sexo, es decir invocación de una divinidad romana precedida de deus, obedezca a un proceso de asimilación (sincretismo) entre un dios indígena con otro del panteón romano) $)^{8}$.

De cualquier forma sobresale la asociación existente (casi identificación) entre Tutela y Genio (ver, por ejemplo, CIL II.2991 = ILS $3667=$ Textos n $^{\circ} 2$, descubierta en Zaragoza y en la actualidad perdida), corroborando en cierto sentido la afirmación recogida en las Actas de los hermanos Arvales: sive deo sive deae in cuius tutela hic lucus locusve est ${ }^{9}$; tampoco podemos olvidar el hecho de que la Tyché helenística aparece mencionada en numerosas ocasiones como «Zeos Tyché», lo que conduciría a esa ambivalencia en zonas más próximas al ámbito helénico.

Si dejamos de lado alguna inscripción hispana en la que la diosa Tutela aparece asociada al culto imperial, como la correspondiente a un centro de población de la provincia de Jaén, cuyo nombre antiguo desconocemos (CIL II.3349= Textos $n^{\circ} 3$ ), o bien la hallada en Tortosa, provincia de Tarragona, en la actualidad desaparecida $\left(C I L\right.$ II.4056 $=$ Textos $\left.^{\circ} 4\right)$, hemos de tomar especial consideración de las dedicatorias a dicha divinidad descubiertas en el arco noroccidental de nuestra Península.

En este contexto, al margen de los monumentos epigráficos dedicados a Tutela Bolgense y Tutela Tiriense (sin duda como protectora de ambas poblaciones o comunidades, y a las que nos referiremos más abajo), sobresale uno hallado en Santiago de Aranza (provincia de Lugo) y en la actualidad perdido (CIL II.2538 = IRG II, p. $149=$ Textos $\mathrm{n}^{\circ}$ 5), así como el encontrado en Aquae Flaviae (Chaves, Portugal), de lectura dudosa (CIL II.5618 = Textos ${ }^{\circ}$ 6), sin olvidar el descubierto en el Castro de Santo Tomé (Orense), en el que únicamente es posible leer TVTELAE en la primera línea y la fórmula votiva $V S L M$ en la última ${ }^{10}$, así como el fragmento de la que se conserva en el Museo Arqueológico de Lugo, cuya difícil lectura solo nos permite reconstruir TVTEL(ae) en la primera de sus líneas ${ }^{11}$.

\footnotetext{
${ }^{6}$ Por ejemplo en ILS 3731 (Tutela optima) hallada en Roma o 4648 (dea Tutela), descubierta en el Périgeux francés.

${ }^{7}$ CIL II.3377: Deo Tutel(ae)/Genio Mentes(orum), comparable a la descubierta en Alhama de Aragón (Zaragoza) [CIL II.3021: Deo Tutel(ae)/ Genio loci].

${ }^{8}$ S.Lambrino, «Les cultes indigènes en Espagne sous Trajan et Hadrien», Les empereurs romains d'Espagne, París 1965, pp.228-229.

${ }^{9}$ ILS 5047.

${ }^{10}$ M.Blanco, «El ara a Tutela del Castro de Santo Tomé (Orense)», Bol.Aur. 1 (1971) 297-298.

${ }^{11}$ F.Vázquez, «Nuevas inscripciones romanas de la provincia de Lugo», BCPMLugo 49-52 (1958-1959) 270-273. Cf. P.Le Roux y A.Tranoy, «Notes d'épigraphie romaine de Galice», CEG 28 (1973) 233.
} 


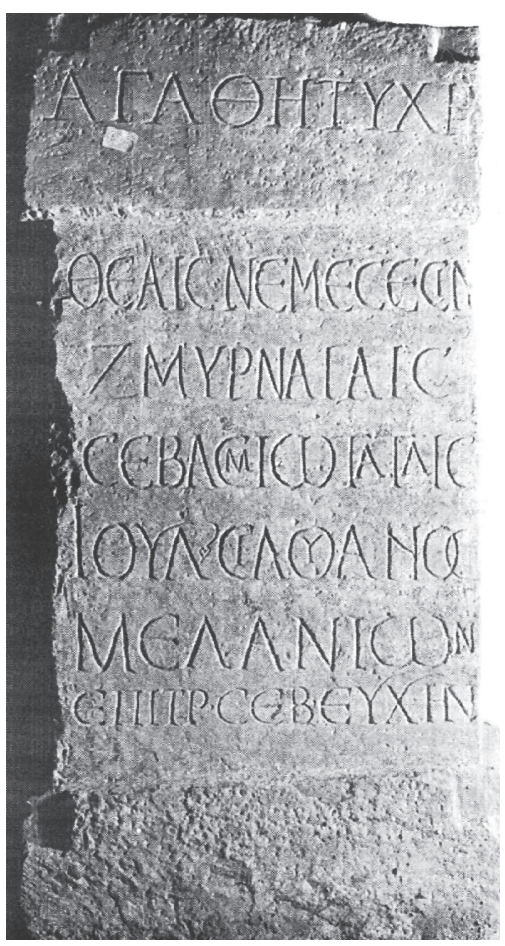

Fig. 85 Estela votiva (en griego) dedicada a la Buena Fortuna y

a Némesis de Esmirna por el procurador Julio Silvano Melanión (Museo de los Caminos, Astorga)

\section{EL CULTO A TUTELA EN ASTURIAS}

Al parecer esta divinidad pasaría a convertirse en protectora de poblaciones enteras, o bien de comunidades organizadas en torno a una civitas, como es el caso de la Tutela de los pésicos, documentada en el suroccidente de Asturias (Textos $n^{0} 7$ ); es más, todos los actuales topónimos Tudela (derivados de Tutela) existentes en territorio hispano, casi en su totalidad en la parte norte de la Península, se relacionan en nuestros días con corrientes fluviales, manantiales y lagunas $^{12}$.

De la misma manera hemos de tener presente, en un contexto similar, que los enclaves conectados con la presencia de aguas salutíferas, tanto de tiempos prerromanos como romanos, contarían como protectores de los mismos con dioses de origen indígena, sincretizados después con los romanos, o bien con divinidades de implantación exclusivamente romana ${ }^{13}$; hemos de destacar especialmente a las ninfas, que se asimilarían a las divinidades de origen prerromano en los mismos ámbitos territoriales en los que era reconocido el poder salutífero de las aguas ${ }^{14}$.

Por ello la Fortuna documentada en la inscripción de Gijón demuestra en su epíteto $\mathrm{Bal}$ nearis su identificación con una divinidad protectora de las aguas (de los baños públicos), presentándosenos como un culto netamente romano sin sustrato indígena alguno (CIL II.2701 $=$ Textos $\left.n^{\circ} 8\right)$.

\section{A. HALLAZGO Y LOCALIZACIÓN DE LA PIEZA}

Pero volvamos al caso concreto del epígrafe descubierto hace más de tres décadas en la localidad de Arganza, en el concejo de Tineo, a pesar de que su estudio y análisis solamente se llevaría a cabo algunos años después: en él parece constatarse la pre-

12 M.J.Pena, «El culto a Tutela en Hispania», p.79. Cf. N.Santos, «El culto a Tutela de Asturias en el marco de la España romana», Tiempo y sociedad 8 (2012) 5 ss. (on line).

${ }^{13}$ F.Díez de Velasco, «Balnearios y dioses de las aguas termales en Galicia romana», AEA 58 (1985) 69 ss.

14 Y esta misma situación se extendería a muchos otros ámbitos geográficos de la Península Ibérica. Cf. N.Dupré y M.J.Pérex, «Thermalisme et religión dans le nord de l'Hispania (des Pyrénées à l'Ebre», Les eaux termales et les cultes des eaux en Gaule et dans les provinces voisines = Caesarodunum 26 (1992) $151 \mathrm{ss}$. 
sencia del núcleo político (civitas) que los romanos adoptaron para organizar desde el punto de vista administrativo, económico y social el territorio correspondiente a la población de los pésicos ${ }^{15}$.

De la misma manera el campo epigráfico correspondiente a este monumento de carácter votivo nos va a permitir solucionar el problema relacionado con la capitalidad de dicha comunidad, echando por tierra otras hipótesis acerca de la ubicación de la misma: la localización de su emplazamiento, así como la proximidad del recinto castreño de San Chuis al lugar del hallazgo de esta dedicatoria votiva, nos ponen en conexión con la articulación romana del territorio, incluidos los abundantes centros de aprovechamiento minero que les rodeaban ${ }^{16}$.

Esta inscripción (dedicada a la divinidad protectora del proceso municipalizador en el Noroeste ${ }^{17}$ ) fue descubierta casualmente el 6 de marzo de 1981 por Julio Antonio Fernández Lamuño (cronista oficial del concejo de Tineo) y por Juan Fernández en el momento en que el primero de ellos trataba de fotografiar el escudo heráldico del palacio de los Francos Flórez, emplazado justamente al lado de la iglesia en que se hallaba empotrado el documento ${ }^{18}$.

Por lo que concierne al monumento epigráfico en sí, evidentemente dislocado de su ubicación originaria, formaba parte de la cobertera del muro de cierre del «cabildo» de la iglesia parroquial (de estilo románico) de Arganza, fechada en los siglos XIXII; se trata de un material pétreo (piedra caliza) que, tras haber perdido su funcionalidad originaria, sería reutilizado como elemento constructivo en la configuración del recinto religioso mencionado ${ }^{19}$.

El palacio de los Francos Flórez, conocido también con el nombre de «Casería de los Valdés», esta ubicado al oeste de la referida iglesia parroquial, de modo que, para elevar su posición y conseguir una mejor perspectiva, el autor de la fotografía subió sobre el muro y descubrió las letras correspondientes al campo epigráfico de la inscripción.

A continuación se realizó una primera lectura y se copió dicho campo epigráfico con algunos errores, comunicándose el día 13 del mismo mes el hallazgo a don Antonio García Linares, quien pocos días después llevaría a cabo la medición, análisis y estudio de la pieza con vistas a su posible publicación (en principio como una pequeña noticia sobre su existencia y significado $)^{20}$.

\footnotetext{
15 Precisamente el carácter romano de dicho enclave viene resaltado en la dedicatoria a Tutela que aparece recogida en dicho documento.

16 Más detalles en N.Santos, «Minería del oro y poblamiento en el norte de la Península Ibérica en época romana», Semanas de Estudios Romanos 9 (1998) 109 ss.

${ }^{17}$ En el ámbito geográfico-administrativo de los galaicos se han detectado igualmente ejemplos de esta realidad. Cf. M.Menor, «Otra ara al dios Tutela», Bol.Aur. 9 (1979) 305 ss.

18 Acerca de la importancia y significado de la llamada «casa de Arganza» remitimos a Z.Méndez García, Los siglos de oro de Tuña, Luarca 1932, p.60.

${ }^{19}$ Esta nueva forma de uso resulta normal en el caso de otros muchos documentos epigráficos, como los que podemos observar formando parte de las murallas de Ávila y Segovia por ejemplo.

${ }^{20}$ A.García Linares y N.Santos, «Nueva lápida romana hallada en Arganza (Tineo, Asturias)», MHA 10 (1989) 151 ss.
} 
En junio del año 1988, momento en que en la capital del concejo de Allande se celebraba, bajo mi dirección, el II Curso de Verano que sobre indigenismo y romanización en el Suroccidente de Asturias la Universidad de Oviedo, con la colaboración del Ayuntamiento allandés, organizaba cada año, se me comunicó el descubrimiento de dicho documento epigráfico, aún inédito, para su revisión.

Seguidamente tuvo lugar, en compañía de D. Antonio García Linares, una visita al lugar de emplazamiento del monumento, iniciándose a renglón seguido el estudio de los aspectos relacionados con su reconstrucción, traducción y comentario, así como con sus características tipológicas $^{21}$.

\section{B. MORFOLOGÍA Y CAMPO EPIGRÁFICO}

Este documento de carácter votivo esta

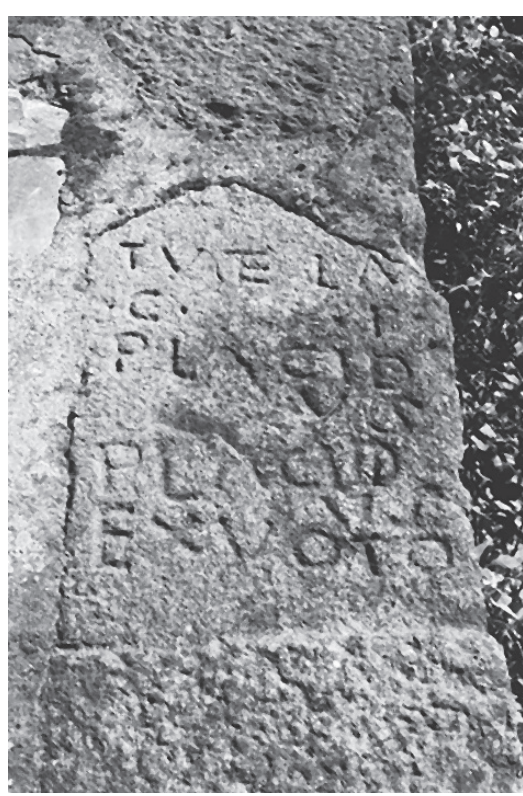

Fig. 86. Dedicatoria a la diosa Tutela (Arganza, Tineo) elaborado en piedra caliza: la pieza, de forma rectangular, nos presenta unas dimensiones totales de $109 \mathrm{cms}$. de altura por 42 de anchura y 23 de grosor; ahora bien, el campo epigráfico, que solo corresponde a la parte superior de la misma, se halla algo rebajado con respecto a la base (zona anepígrafa), cuyas mediciones se sitúan en torno a 46 x 42 x $25 \mathrm{cms}$.

La medida de las letras grabadas oscila entre 4 y 7 cms., presentándonos algunas características significativas:

1. Las A no llevan travesaño interior (por lo que se asemejan a una $V$ invertida).

2. En la primera línea del campo epigráfico hallamos un nexo (unión) entre las letras T y E.

3. El final de esa misma línea puede interpretarse como un nexo entre A y E, o bien como la falta de $\mathrm{E}$ por erosión o fragmento del soporte del documento.

4. Las letras C y P de la segunda línea cuentan con interpunciones, antes y después de cada una de ellas.

5. En el final de la quinta línea hallamos una I inscrita dentro de la D.

El monumento analizado dispone de un pequeño rebaje en la parte inferior izquierda de la base, sin duda destinada a usos posteriores al momento de su erección; por su parte el mortero con que se sujeta, por su parte posterior y superior, con el murete de referencia no nos permite conocer, en el estado actual de conservación

\footnotetext{
${ }^{21}$ En la actualidad esta pieza se conserva en la Casa de Cultura de Tineo. Cf. N.Santos, Asturias, los astures y la administración romana durante el Alto Imperio, Oviedo 2009, pp.177 ss.
} 
de la pieza, la morfología originaria de la inscripción ni definir, dada su naturaleza votiva, si contaba o no con foculi destinados a la quema de perfumes y ofrendas a la divinidad venerada.

\section{UBICACIÓN EN EL TERRITORIO ASTURIANO}

Para comprender el significado históricos de este documento se hace preciso enmarcar el lugar del hallazgo y su contextualización en época romana, a pesar de que no sabemos con seguridad cual sería su ubicación originaria; la población de Arganza se halla emplazada al sur del concejo de Tineo, en un territorio muy próximo al de los concejos vecinos de Allande y Cangas del Nancea: su suelo aparece cruzado por la corriente fluvial del mismo nombre, tributaria a su vez del río Narcea, transitando igualmente por ella la carretera que enlaza Gera y El Puelo.

El asentamiento de la lápida dista aproximadamente $20 \mathrm{kms}$. de Tineo (capital del concejo del mismo nombre), unos 15 de Pola de Allande y unos 13 de Cangas del Narcea, centros de población más significativos de la región ${ }^{22}$.

La parroquia de Arganza abarca todo un conjunto de unidades menores de población habitadas en la actualidad: Agüera de Carriles, Arganza, La Llana, Moure, Rozadiella, Semellón de Abajo, Semellón de Arriba y Villarmou; en este suelo parecen haber estado emplazados al menos dos recintos castreños, el conocido como Castillo de los moros, que estaría situado en el término de Agüera ${ }^{23}$, mientras que el segundo es denominado El Rebollar, que fue descubierto, al igual que el anterior por D.José Lombardía Zardaín (el centro de población antigua es conocido por los paisanos de la zona simplemente con el nombre de El Castro) ${ }^{24}$.

Dicho núcleo de habitat dista en línea recta aproximadamente unos $150 \mathrm{~ms}$. de la iglesia parroquial de la localidad de Arganza en dirección este, aguas abajo del río y a unos $20 \mathrm{~ms}$. de su cauce en la margen derecha.

Ningún indicio nos lleva a conectar la inscripción con alguno de los recintos fortificados próximos, tanto los emplazados en el suelo del vecino concejo de Cangas del Narcea como el recinto de San Chuis, en las proximidades de la población de San Martín de Beduledo (concejo de Allande).

El único centro de población (sin excavar, al igual que los anteriormente mencionados) que pudo reunir unas características apreciables para ser objeto de esta adjudicación lo sería el conocido con el nombre de El Castiello ${ }^{25}$, cuya ubicación se corresponde con la confluencia del Narcea con el Arganza, conocido además como

\footnotetext{
${ }^{22}$ N.Santos, «La inscripción de Arganza (Tineo) y la población de los pésicos entre los astures transmontanos», Lancia 5 (2005) 167 ss.

23 J.M.González, Historia general de Asturias, 2: Asturias protohistórica, Salinas 1977, p.209.

${ }^{24}$ Sería visitado por D.Antonio García Linares el día 10 de septiembre de 1981 en compañía de su descubridor.

${ }^{25}$ C.Saenz Ridruejo y J.Vélez, Contribución al estudio de la minería primitiva del oro en el Noroeste de España, Madrid 1974, pp.122-125.
} 
«Casa de los moros»: en la actualidad se identifica con los restos de una torre o castillo medieval (el castillo-fortaleza de Santa Cruz de Ovilley), que se menciona en la documentación de los siglos XII y siguientes ${ }^{26}$.

\section{TOPONIMIA Y ANTROPONIMIA}

Pero, ¿cuál es el origen y significado del topónimo Arganza? Para algunos investigadores este nombre de lugar remontaría ya a la historia prerromana de la región ${ }^{27}$, mientras que otros consideran que presenta conexiones evidentes con el vascuence $^{28}$.

En el mismo territorio de Asturias nos encontramos con el topónimo Argandenes, correspondiente a un lugar de la parroquia de Villa, en el concejo de Piloña; dicha denominación de lugar parece derivar de la población antigua conocida como luggones arganticaeni, que aparecen reflejados en un ara votiva hallada en la localidad de Grases y que en la actualidad se encuentra ubicada a la entrada de la iglesia de la misma $^{29}$.

De cualquier forma no debemos olvidar que esta región correspondiente al valle del Arganza se relaciona con uno de los distritos o enclaves de aprovechamiento aurífero más significativos de época romana, tanto por lo que respecta al concejo de Tineo como a los próximos de Cangas del Narcea y Allande, por los que discurre con anterioridad a su entronque con el Narcea ${ }^{30}$.

Cuestión distinta es la que se refiere a los nomina del dedicante de la inscripción: el primero de ellos (Placidus) lo encontramos con relativa frecuencia en la onomástica del territorio ibérico durante los siglos de cultura romana ${ }^{31}$, mientras que el segundo de los componentes de la antroponimia del personaje (Placidius) nos aparece registrado epigráficamente en un número de ocasiones mucho menor, y además como componente primero (y no segundo, como sucede en esta oportunidad) ${ }^{32}$.

A este respecto descubrimos un paralelismo contrario, es decir los dos nomina alterados, al de Placidio Plácido, veterano de la legión VII Gemina Alexandriana,

\footnotetext{
${ }^{26}$ En realidad el lugar contaría con un asentamiento castreño, reutilizado en tiempos visigodos y sobre el que se construiría después el centro-fortaleza en época medieval.

${ }^{27}$ M.Sevilla, Toponimia de origen indoeuropeo prelatino en Asturias, Oviedo 1984, pp.31-33.

${ }^{28}$ J.Uría, El libro de Asturias, Oviedo 1970, p.60. Cf. J.L.García Arias, Pueblos de Asturias: el porqué de sus nombres, Salinas 1977, p.91.

${ }^{29}$ Para más detalles remitimos a E.Alarcos, «Luggoni arganticaeni», Homenaje al profesor Cayetano de Mergelina, Murcia 1962, pp.31-34.

30 Ver, por ejemplo, N.Santos, «Las explotaciones romanas de oro de la cuenca del Arganza en el concejo de Allande (Asturias)», SH (Ha Antigua) 20 (2002) 201 ss.

${ }^{31}$ CIL II.2523: Antistius Placidus; Pompeius Placidus (J.M.Blázquez, Religiones primitivas de Hispania, Roma 1962, p.103); Ambatus Placidus (E.Marcos, «Nuevas lápidas vadinienses de la provincia de León», Tierras de León 14 (1971) 77); CIL II.2469: Quintus Fulvius Placidi filius (J.M.Blázquez, Religiones primitivas, p.132); CIL II.2655: Placidus C.Licinii Himeri servus...

${ }^{32}$ Entre otros, remitimos a los casos de Placidius Lucius (CIL II.4394); Placidius Placidus (CIL II.2640); Placidius Seneca (CIL II.5637); Placidius Severus (CIL II.4394); o Placidia Modestis (CIL II.455).
} 
de 57 años de edad, de acuerdo con su lápida sepulcral descubierta en Asturica Augusta ${ }^{33}$.

Posiblemente la no presencia de la nomenclatura completa de los antropónimos de dicho personaje (tria nomina) pudiera obedecer al hecho de que los habitantes libres de la zona se hallaban inmersos en ese proceso, aún inconcluso, del paso de la organización administrativa indígena a la romana, por lo que todavía no habría recibido la confirmación definitiva de su integración jurídica en el estatuto privilegiado romano de ciudadano, aunque fuese con el derecho latino únicamente ${ }^{34}$.

Este proceso de adaptación a la normativa político-administrativa romana, derivado posiblemente de la aplicación (en una época tardía con respecto a otras regiones del territorio hispano) de la ley Flavia municipal (lex Flavia municipalis) al Noroeste peninsular, supondría no sólo la latinización de los antropónimos del personaje sino también el cambio de filiación que hasta ese momento había regido para dichas comunidades.

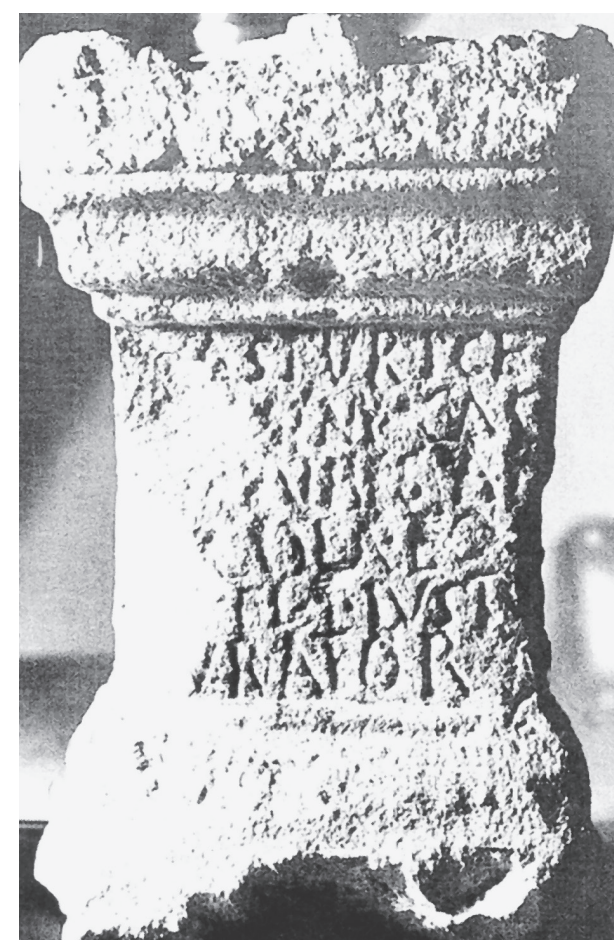

Fig. 87. Altar dedicado al genio de los asturicenses (Museo de los Caminos, Astorga)

Como consecuencia la expresión de las relaciones paterno-filiales de la época anterromana, que se mantendrían vigentes durante prácticamente todo el siglo I d.C. (ver, por ejemplo las inscripciones del soldado Pintaio ${ }^{35}$ o de Flavio Cabarco ${ }^{36}$ ) se transformaría durante la segunda centuria de nuestra era hasta desaparecer por completo.

Sabemos que en otras zonas de la Península este hecho conllevaría que la origo (radicación, nacionalidad, pertenencia a una civitas concreta) se explicaría a través

${ }^{33}$ CIL II.2640: D(is) I(nferis) M(anibus)/ Placidio/ Placido vet(erano)/ leg(ionis) VII G(eminae) Alex/ sandrianae p(iae) f(elicis)/vixit an(nos) LVII/ Papiria Maximina marito/ incomparabi/li memoriam/posuit. Cf. N.Santos, El ejército romano y la romanización de los astures, Oviedo 1981, pp.242-243.

${ }^{34}$ Contrasta así con el soldado veterano de Astorga que acabamos de mencionar, cuya situación personal como ciudadano haría pensar en la presencia de tria nomina en este documento votivo.

${ }^{35}$ CIL XIII.8098 = ILS 2580: Pintaius Pedilici/f(ilius) astur trans/ montanus castello/ Intercatia signifer/ c(o)h(ortis) V Asturum/ ann(orum) XXX stip(endiorum) VI(I?)/ h(eres) ex t(estamento) f(aciendum) c(uravit). Cf. N.Santos, «Lápida funeraria del siglo I d.C. dedicada al astur Pintaius», Nuestro Museo 1 (1997) 39 ss.

${ }^{36}$ CIL II.5739: Flaus (Flavus o Flavius)/Auledi f/ Cabarc/ us c(astro) o c(astello) Beri/ so an(norum)/XV h(ic) s(itus) e(st). Cf. N.Santos, «Lápida funeraria de Flavius Cabarcus», Nuestro Museo 1 (1997) 125 ss. 
del gentilicio del centro urbano al que se estaba adscrito, añadiéndose además los tria nomina como distintivo de ciudadano de dicho núcleo político-administrativo.

En nuestro caso ese cambio estaría aún en fase de acomodación a la nueva normativa romana promulgada en tiempos de los Flavios (Vespasiano), de manera que es posible pensar que la primera mitad del siglo II d.C. (época de Trajano y Adriano principalmente) estaría ocupada en esta fase de inclusión de las comunidades indígenas (la de los pésicos entre ellas) en las formas organizativas romanas; y de ahí que el dedicante de la inscripción todavía no haya recibido los tria nomina como expresión de que ese proceso de adaptación a la organización político-administrativa romana se hubiera producido ya completamente.

\section{E. SIGNIFICADO HISTÓRICO DE LA INSCRIPCIÓN}

Las mayores vacilaciones parecen proceder de la lectura (reconstrucción) e interpretación de las letras C y P reflejadas en la segunda línea del campo epigráfico: creemos que tales iniciales deben interpretarse como la abreviatura de una unidad gentilicia en sentido amplio la segunda de ellas, mientras que la primera se vincula con el centro administrativo (capital) de la misma ${ }^{37}$.

Por otro lado el documento epigráfico estaba dedicado a una divinidad bienhechora (además de relacionarse con el proceso de municipalización intensificado por la política de los Flavios en el Imperio), concretamente a la Tutela de una población (unidad gentilicia suprafamiliar), como parece haber sido el caso, igualmente en territorio de los astures, de la Tutela Bolgensis (Textos $\left.n^{0} 9\right)^{38}$ o a la Tutela Tiriensis $\left(\text { Textos } n^{\circ} 10\right)^{39}$.

A las 16 inscripciones latinas consagradas a Tutela que aparecen catalogadas ya por Hübner en el volumen del Corpus Inscriptionum Latinarum correspondiente a Hispania hemos de añadir los monumentos de esta naturaleza encontrados en diferentes enclaves ${ }^{40}$, como por ejemplo el descubierto en Orense ${ }^{41}$, o el hallado en la ciudad de $\mathrm{Lugo}^{42}$, constituyendo la inscripción de Arganza el primer testimonio consagrado a dicha divinidad de la región asturiana.

La cuestión se plantea en los términos siguientes: ¿a qué grupo de población de los astures se refiere esta lápida encontrada en Asturias? Por una parte hay que tener

\footnotetext{
37 A pesar de que resulte sumamente difícil determinar la ubicación de su emplazamiento.

38 J.M.Blázquez, Religiones primitivas de Hispania I, Roma 1962, p.63 (ara de granito descubierta en Cacabelos). Cf. M.A.Rabanal y S.García, Epigrafía romana de la provincia de León: revisión y actualización, León 2001, pp.78-79, $\mathrm{n}^{\circ} 26$ (ver igualmente p.80. $\mathrm{n}^{\circ}$ 27, referido a la Tutela Cal(vensis?).

39 J.M.Blázquez, Religiones primitivas de Hispania, p.63 (ara encontrada en Santa María de Ribeira Pinhae, Portugal).

40 Y recogidos por M.J.Pena [«El culto a Tutela en Hispania», pp.84-86].

41 Bol.Aur. 1 (1971) 296 ss.

42 N.Ares Vázquez, «Revisión de cuatro inscripciones romanas», BCPMLugo 81-84 (1974-1975) 174177, que había sido interpretado por P.Le Roux y A.Tranoy [CEG 28 (1973) 233] como dedicatoria a Tutela Bolgensis.
} 


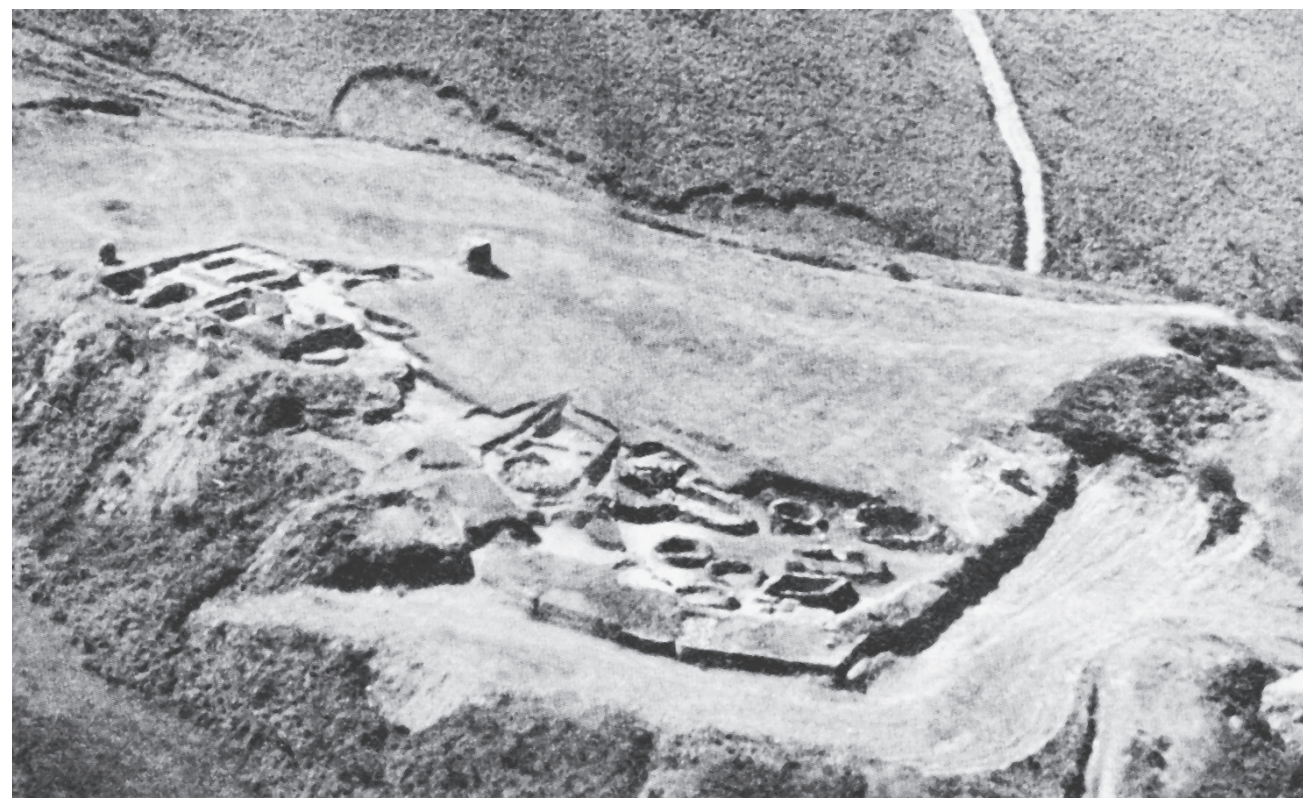

Fig. 88. El castro de San Chuis (Allande), ¿capital de los pésicos?

en cuenta la proximidad del núcleo de población castreña de Arganza, emplazado a una altitud relativamente baja ${ }^{43}$, así como la presencia en sus alrededores de un conjunto de tajos y cortas mineras de oro ${ }^{44}$.

Por otro lado hemos de añadir que este enclave de habitat castreño esta asentado en el recorrido de una vía de enorme importancia durante todas las épocas históricas, la correspondiente a Tineo-Arganza-Cangas del Narcea, cuya importancia arranca de época romana pero que se prolongaría durante la etapa medieval (en conexión directa o indirecta con el Camino de Santiago), moderna y contemporánea ${ }^{45}$.

\section{F. LOS PÉSICOS Y EL SUROCCIDENTE DE ASTURIAS}

El poblado castreño de Arganza, que tal vez haya que identificar con el centro o capital del territorio de los pésicos (y de ahí que adquiriese las connotaciones inhe-

\footnotetext{
43 A poco más de 300 ms., lo que no deja de ser llamativo. Cf. J.M.González, Historia de Asturias Ayalga 2: Asturias protohistórica, p.21.

${ }^{44}$ En este sentido el emplazamiento de la civitas Paesicorum, cualquiera que fuese, coincidiría con una zona de supervisión y control de los centros mineros de los «distritos» más amplios y mejor aprovechados de todo el Suroccidente asturiano. Ver, por ejemplo, N.Santos, «La vía de Pola de Allande a Grandas de Salime (vía romana del Puerto del Palo)», ETF (Ha Antigua) 13 (2000) 425 ss.

45 G.M.de Jovellanos, Diarios, Oviedo 1954, pp.14, 17, 281 y 286.
} 
rentes a una civitas astur-romana), agruparía, desde el punto de vista administrativoterritorial, a una serie de poblaciones circundantes.

De esta manera es posible que llegase a erigirse en el elemento vertebrador de la vida de una parte de la población antigua que los autores grecolatinos mencionan como comunidades o grupo de los pésicos; según las indicaciones de Plinio ${ }^{46}$, además de configurar una de las agrupaciones más significativas de los astures, los pésicos estarían ubicados, al describirnos la costa cantábrica, al occidente de una península del territorio de los astures, que sin duda corresponde al cabo Torres (Campa Torres) en Gijón.

Igualmente el geógrafo Ptolomeo los localiza entre los galaicos lucenses y los cántabros, atribuyéndoles por la costa la desembocadura del río Nalón y el centro urbano de Flavium Avia = Flavionavia ${ }^{47}$, que con toda probabilidad hemos de emplazar en la zona de Pravia, y más en concreto en Santianes de Pravia.

La alusión que Pomponio Mela realiza sobre ellos ${ }^{48}$ no resuelve los problemas de la indeterminación geográfica ptolemaica; ese espacio tan extenso que les asigna (en especial en el litoral costero) parece corregirse precisamente a través de la inscripción de Arganza.

En una fase avanzada de la Antigüedad el primitivo centro fortificado de Arganza se identificaría con el asentamiento de la mansión o ciudad de Passicin ${ }^{49}$, continuando sin duda desarrollando las funciones propias de núcleo administrativo de los pésicos.

Teniendo presentes dichas indicaciones este grupo de los astures se localizaría desde el Navia (o Esva-Canero) hasta Gijón por la costa, mientras que por el interior habitarían el suelo que se extiende hasta el concejo cangués, ocupando ambas márgenes del río Narcea y sus respectivos afluentes; de este modo ocuparían el territorio actual de los concejos de Somiedo, Miranda, Cangas del Narcea, Allande, Tineo y Salas fundamentalmente, conservando su denominación originaria en el transcurso de los siglos visigodos y hasta bien avanzada la época medieval.

Es posible constatar también su presencia en la documentación numismática de época visigoda: tanto en una pieza de oro cuya emisión corresponde a Sisebuto como en el triente aculado con anterioridad en tiempos de su predecesor Gundemaro ${ }^{50} \mathrm{se}$ nos muestra la ceca de emisión Pesicos.

Pero es que, además de la forma Passicin con que nos muestra documentado el centro político-administrativo de dicha población el Anónimo de Rávena, que respondería posiblemente al ablativo Passicis o Paesicis de los Itinerarios antiguos,

\footnotetext{
${ }^{46}$ Historia Natural 4.20.111. Ver igualmente 3.3.28.

47 2.6.65. Cf. N.Santos, «Flavionavia, una ciudad romana en la frontera del Imperio», SH (Ha Antigua) 16 (1998) 123 ss.

48 Chorographia 3.28.

49 Anónimo de Rávena 320.17.

${ }^{50}$ Más detalles en N.Santos y C.Vera, «Acuñaciones visigóticas en el Occidente de Asturias», Rutas, ciudades y moneda en Hispania, Madrid 2000, pp.441-448, y, de los mismos autores, «Pésicos y las acuñaciones visigodas en Asturias», Numisma 49 (2000) 57ss.
} 
los pésicos (y/o su capital Pesicos) aparecen mencionados bajo otras denominaciones; es el caso de Pesicoe en la relación de poblaciones correspondiente al concilio celebrado en Lugo en el 569, en la que se incluyen las iglesias asignadas al obispo de Astorga ${ }^{51}$.

Incluso en una época más avanzada (del siglo VIII al XII a causa de la indeterminación que acompaña a la fecha de su redacción) es posible descubrir una transcripción, posiblemente errónea, de este mismo término en la Hitación de Wamba, donde aparece reflejado como Pericoe.

En los siglos medievales, a través de la documentación diplomática, encontraremos referencias a dicha población (o bien a su capital, o al territorio ocupado por ella) en una serie de textos que se fechan desde el siglo IX al XIII ${ }^{52}$; de entre ellos vamos a destacar, como uno de los ejemplos más significativos, el fechado en el año 1031, donde se puede leer: In territorio Asturiense, in valle que dicunt pesiccis, super Alveos decurrentes Narceija et Luigna, con lo que un amplio grupo de los pésicos se hallaría ubicado en el suelo de Cangas del Narcea, ya que tanto el río Narcea como el Luiña (Naviego) constituyen corrientes fluviales que tienen su nacimiento y recorrido en el mencionado concejo.

\section{G. LA CIVITAS DE LOS PÉSICOS}

La agrupación poblacional de los pésicos, integrada en el populus de los astures, constituiría una unidad social de gran amplitud ${ }^{53}$, cuyo suelo habitado hay que identificar con la región occidental asturiana, en concreto y de manera especial el territorio que se extiende por la cuenca baja del río Nalón, así como por las correspondientes al Pigüeña y Narcea, contando con la corriente fluvial del Navia (o del Esva-Canero) como límite máximo de expansión ${ }^{54}$.

Como consecuencia de ello la inscripción que estamos analizando no haría más que confirmar esa hipótesis, de manera que las letras $\mathrm{C}$ y $\mathrm{P}$ de la misma se referirían expresamente a la $C$ (ivitas) $P$ (aesicorum).

Este conglomerado de gentes, que configuraría la población antigua más importante del Occidente de Asturias, ocuparía, de acuerdo con la división administrativa romana en conventus jurídicos, el territorio limítrofe entre astures y galaicos, teniendo como vecinos a la población galaica de los albiones en las márgenes del río Navia ${ }^{55}$.

\footnotetext{
51 A.Tranoy, La Galice romaine. Recherches sur le Nordóuest de la Péninsule Ibérique dans l'Antiquité, París 1981, p.50.

52 J.M.González, El litoral asturiano en la época romana, pp.198-201 y 214-217.

${ }^{53}$ F.J.Lomas, Asturia prerromana y altoimperial, Sevilla 1975, p.256.

${ }^{54}$ Dicha zona se corresponde además con el espacio propio del bable occidental. Cf. J.M.González, Antiguos pobladores de Asturias, Salinas 1976, pp.108-109.

${ }^{55}$ N.Santos, «La inscripción de Nicer hallada en La Corredoira (Vegadeo) y los albiones (galaicos) del Occidente de Asturias», En torno al bimilenario del Eo, Oviedo 2002, pp.279 ss.
} 
Ptolomeo se refiere, en los comedios del siglo II, a la existencia entre los habitantes de la Asturias de su época de dos núcleos de población de cierta relevancia, el primero de los cuales, Flavionavia, estaba ubicado en territorio de los pésicos (2.6.5), no volviendo a aparecer con posterioridad en las fuentes literarias, mientras que el segundo, Lucus Asturum, se registra en la diplomática medieval y en escritos posteriores con cierta asiduidad ${ }^{56}$.

Dado que este centro de población antigua solamente es mencionado por el geógrafo de Alejandría (y ya en la fase final del Alto Imperio), se ha relacionado a Flavionavia con el centro de población más representativo del grupo social de los pésicos (confundiéndolo en ocasiones con la capital de dicha población), que sería utilizado como enclave de relaciones marítimas y comerciales (unos objetivos que no perdería en los siglos medievales y modernos).

Teniendo en cuenta los grados de latitud que la asigna Ptolomeo, distintos a los de la desembocadura del Nalón, aunque no los ubica a una gran distancia entre ellos, habría que situar a Flavionavia en las márgenes de esa corriente fluvial y siempre en los alrededores de Pravia (en ningún caso en la actual capital del concejo), no muy lejos del litoral y un poco hacia el interior ${ }^{57}$.

El emplazamiento de este centro urbano de los astures en época romana ha suscitado opiniones divergentes, aunque todas coinciden en situarlo en las inmediaciones de la costa y en los aledaños de alguna corriente fluvial de cierta consideración; nos encontramos ante el puerto de salida de la producción aurífera de una parte de los yacimientos mineros de la cuenca del Narcea, en especial si tenemos en cuenta que la ría del Nalón constituiría un punto de evacuación del oro y de otros productos agropecuarios de la región por medio de la escuadra romana del Cantábrico ${ }^{58}$.

Así, desde hace siglos se viene proponiendo su localización en la capital del concejo de Navia, tras descomponer el topónimo ptolemaico en dos (Flavio y Navia), y tener presentes las características que nos ofrece la ría de la corriente fluvial homónima en la actualidad (los poblados castreños de Coaña y Armental en sus dos márgenes, que controlaban y flanqueaban la bocana de entrada y salida al mar; Coaña como centro de recepción de los productos auríferos obtenidos en las explotaciones mineras del distrito Ibias-Narcea; la posibilidad de que en dicha ría recalase cada cierto tiempo la escuadra del Cantábrico; la presencia de murias y topónimos antiguos, algunos de ellos vinculados con asentamientos agropecuarios en los lugares más llanos del

\footnotetext{
${ }^{56}$ El significado de este núcleo de habitat de los astures transmontanos requiere un análisis monográfico, puesto que su importancia se acrecentaría al convertirse en centro de comunicaciones viarias (el hallazgo en su solar de una inscripción dedicada a los Lares Viales así lo confirma).

Como adelanto remitimos a nuestro «Avance al estudio de la ciudad romana de Lucus Asturum (Lugo de Llanera, Asturias)», El territorio de las ciudades romanas, Madrid 2008, pp.425 ss.

57 Algunos autores, como Diego Santos, siguiendo las indicaciones de José Manuel González, creen que se trataría del hito final de la Vía de la Mesa, que, proveniente del territorio leonés, llegaría hasta la costa cantábrica.

58 Sobre estas cuestiones cf. N.Santos, «La evacuación del oro de Asturias en dirección a Roma», II Congreso Peninsular de Historia Antigua, Coimbra 1994, pp.917 ss.
} 
territorio; el trazado de la red viaria romana, próximo al litoral, cuya continuación se rastrea igualmente en tiempos visigodos y medievales $)^{59}$.

Se inclinan por su ubicación en la capital del concejo de Valdés (Luarca), sin argumento alguno que aclare dicha elección, investigadores como el Padre Flórez (considera que es en dicho territorio donde debe emplazarse la península de los pésicos a la que se refieren los autores antiguos $)^{60}$; por su parte Bosch Gimpera y Aguado Bleye ${ }^{61}$ lo sitúan en la región de Pravia sin ningún detalle

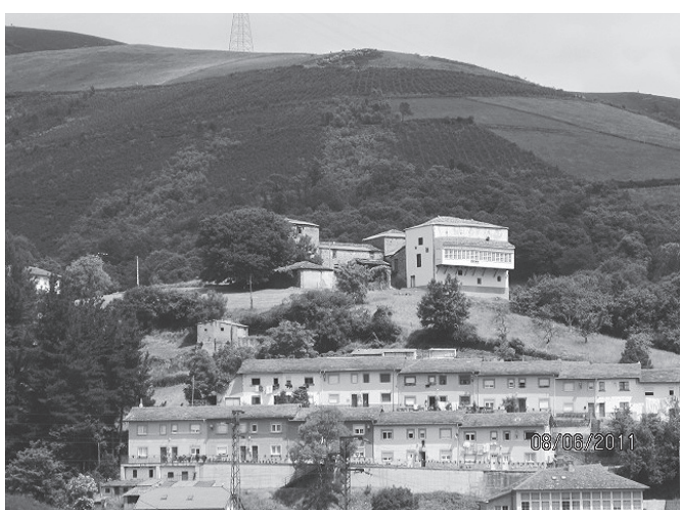

Fig. 89. El recinto castreño de Cimadevilla (Pola de Allande) desde la explotación romana del Bachicón de Fresnedo que añadir al respecto, donde todavía en la actualidad alcanza con cierta facilidad la pleamar de la ría del Nalón ${ }^{62}$.

La historiografía actual converge en colocar este centro de población en las proximidades de Pravia, y más en concreto en Santianes de Pravia, no solo por la documentación histórica (restos arqueológicos sobre todo) sino también por su continuidad de poblamiento desde una época muy antigua, a pesar de que no se correspondería con la capitalidad de los pésicos, como se ha pretendido en ocasiones de forma equivocada ${ }^{63}$.

En este sentido los restos materiales hallados en esa aldea praviana o en sus inmediaciones, entre los que destacan (la villa romana de la Magdalena de la Llera ${ }^{64}$; la villa romana sobre la que se construiría después la iglesia dedicada a san Juan, sin duda aprovechando la existencia de una capilla o recinto paleocristiano; los topónimos de raíz latina de la zona; los restos de construcciones antiguas, fragmentos de cerámica fina, tejas planas y barros toscos, cocidos y sin esmalte, hallados en el valle de Posada en Bances; sepulturas con restos humanos y fragmentos de inscripciones sepulcrales de tiempos romanos ${ }^{65}$; la estela del togado de Los Cabos $^{66}$...) denotan

\footnotetext{
59 Dicha hipótesis arranca de Riesco, Madoz y Ceán Bermudez, habiendo sido defendida después por Fernández Guerra, A.Blázquez, Somoza, Sánchez Albornoz, López Cuevillas y Schulten (quien recoge, en parte al menos, la opinión de sus predecesores en su Geografía y etnografía antiguas de la Península Ibérica, Madrid 1959, pp.107-108).

${ }^{60}$ En España Sagrada 15, pp.46-47.

61 Historia de España de R.Menéndez Pidal, Madrid 1935, 2, pp.260 y 268.

${ }^{62}$ Las distintas hipótesis se recogen en J.Santos, «Asturias en la organización político-administrativa romana de Hispania en época altoimperial», Historia general de Asturias, Gijón 1982, 1, pp.154-155.

${ }^{63}$ Ver, por ejemplo, J.M.González, «Flavionavia, antigua población de los pésicos», BIDEA 18 (1953) $32 \mathrm{ss}$.

64 J.G.Gorges, Les villas hispanorromaines, París 1979, p.333.

${ }^{65}$ Elementos descritos por F.de Selgas, La primitiva basílica de Santianes de Pravia (Oviedo), Madrid 1902.

${ }^{66}$ N.Santos, «La inscripción de Ario Sestio hallada en Los Cabos (Pravia) y su posible vinculación con la ciudad astur-romana de Flavionavia», Nuestro Museo 2 (1998) 173 ss.
} 
un proceso de romanización, incluido un aprovechamiento intensivo (agropecuario) de los recursos económicos de la zona en tiempos romanos, en especial durante el Bajo Imperio.

\section{H. EL PROCESO DE MUNICIPALIZACIÓN}

La presencia de la diosa Tutela en la inscripción de Arganza nos pone en contacto con un hecho enormemente significativo para las poblaciones astures: el inicio de su integración en el marco de la administración romana a través del proceso de municipalización (que no de urbanización en el sentido de creación de núcleos urbanos de nueva planta) en el cuadrante noroccidental hispano ${ }^{67}$.

Hasta hace no mucho tiempo se creía tradicionalmente que el ius Latii solo había tenido consecuencias visibles sobre las comunidades o individuos que habitaban el sur y levante peninsulares, en los que estaba arraigado un desarrollo más avanzado de las formas de vida a la manera romana con base en la ciudad ${ }^{68}$.

Las poblaciones asentadas en el territorio septentrional hispano, incluida Gallaecia, se organizarían y funcionarían de acuerdo con las normas de comportamiento político-administrativo romano a partir de la época de los Flavios, aunque este hecho no traería consigo la fundación de nuevos centros urbanos; en consecuencia no se concedería el status de municipio a ninguno de los núcleos de habitat indígena, ni tampoco el de colonia a las hipotéticas ciudades de nueva creación, asignándoseles en cambio la situación jurídico-territorial de civitas $^{69}$.

De esta manera las referencias de Estrabón vinculadas a la organización políticoadministrativa romana de las poblaciones septentrionales tras los años de conquista ${ }^{70}$ inciden en el hecho de que la presencia de tres cuerpos legionarios en la cornisa cantábrica contribuiría no sólo a la pacificación de dichas poblaciones sino también a la civilización de las mismas ${ }^{71}$; además, la desmilitarización del Norte peninsular culminada por Vespasiano (con una sola legión en el mismo) se corresponde cronológicamente con la intensificación del aprovechamiento de los recursos auríferos y con el avance del proceso de municipalización ${ }^{72}$.

\footnotetext{
${ }^{67}$ El ius Latii llevaría implícitas la urbanización y municipalización de las distintas regiones hispanas. Cf. A.Caballos, «Latinidad y municipalización de Hispania bajo los Flavios. Estatuto y normativa», Mainaké 23 (2001) 101 ss.

68 P.Le Roux y A.Tranoy, «Rome et les indigènes dans le Nord-ouest de la Péninsule Ibérique. Problémes d'épigraphie et d'histoire», MCV 9 (1973) 77 ss.

${ }^{69}$ G.Pereira, «La formación histórica de los pueblos del Norte de Hispania. El caso de Gallaecia como paradigma», Veleia 1 (1984) 286.

70 Geografia 3.4.20. Comparar, y completar, con 3.3.8.

71 Por este motivo las poblaciones septentrionales abandonarían sus formas de vida tradicionales, pasando a organizarse como polis o civitas.

${ }^{72}$ N.Santos, «El final de las guerras astur-cántabras y la desmilitarización del ejército romano en territorio de los astures», ETF (Historia Antigua) 17-18 (2004-2005) 237 ss. y «La consolidación del ejército romano de ocupación en territorio de los astures (años 20-68)», Sautuola 12 (2006) 112 ss.
} 
Todos estos hechos no pueden interpretarse únicamente como exponentes de una mayor pacificación de la zona, sino que constituyen simultáneamente indicadores evidentes de que se había producido ya una verdadera integración ${ }^{73}$; en este contexto es posible concretar la datación de la inscripción de Arganza en las décadas finales de la primera mitad o en las intermedias del siglo II d.C. (época de Adriano o Antonino Pío), teniendo presente que la descripción geográfico-histórica de las Tablas de Ptolomeo (2.6.5) no menciona dicho centro, asignando tal vez por ello equivocadamente a Flavionavia la capitalidad de los pésicos.

De ello parece desprenderse (en el marco de la municipalización del Occidente de Asturias) que el poblado castreño de Arganza (a identificar con la $\mathrm{ci}$ vitas Paesicorum) ${ }^{74}$, que posteriormente parece identificarse perfectamente con la mansión Passicin en el recorrido de la vía que enlazaba Lucus Asturum con Lucus Augusti, vendría caracterizado por un conjunto de elementos comunes a los centros indígenas organizados a la manera romana.

Esta forma de administración del

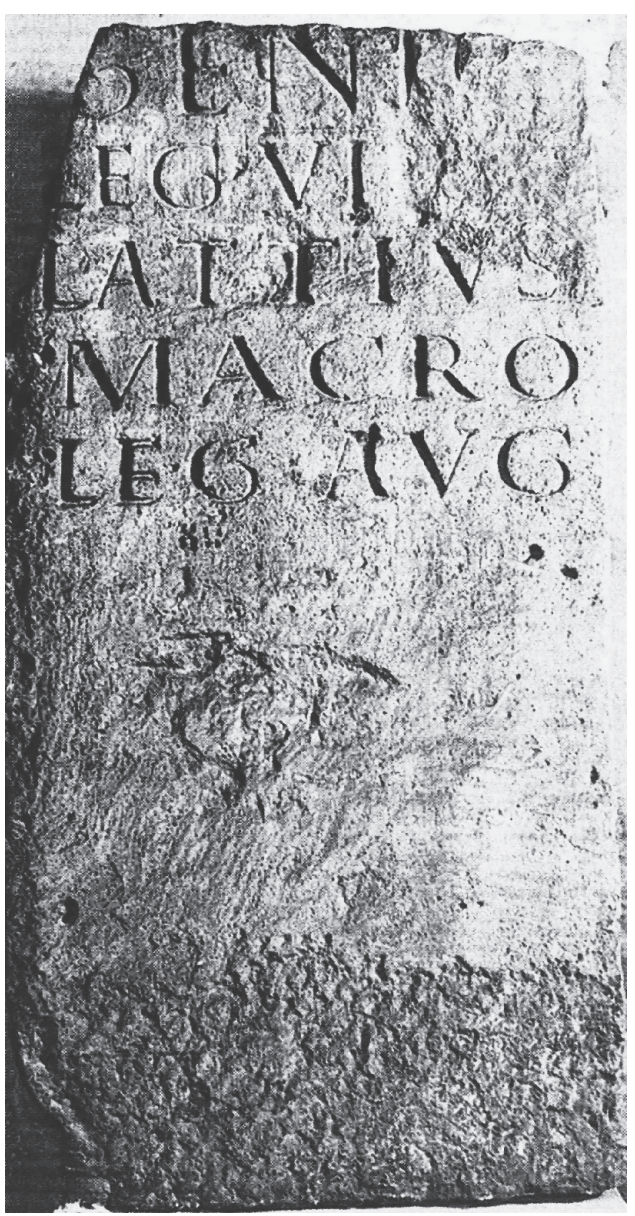

Fig. 90. Dedicatoria al genio de la legión VII en León suelo indígena por parte del Estado romano comportaba que estos núcleos de habitat destacasen por su situación estratégica, así como por dar acogida a un grupo de soldados más o menos amplio, su función como receptáculo de los productos auríferos extraídos en su distrito minero, su conexión con vías de comunicación significativas (o ser ellos mismos cruces relevantes de caminos) y su realce como centro político (administrativo, económico y religioso) de comunidades más o menos numerosas.

\footnotetext{
73 J.J.Sayas, «Municipalización de la Hispania romana. Ideología y realidad», Centralismo y descentralización. Modelos y procesos históricos en Francia y España, Madrid 1985, pp.120-121.

${ }^{74} \mathrm{Y}$ sin desarrollar la hipótesis de su posible vinculación con el recinto de San Chuis en el vecino concejo de Allande.
} 


\section{ANEXO DOCUMENTAL}

1. Inscripción al dios Tutela procedente de Tarraco

$$
\begin{array}{cc} 
& \text { DEO TVTE } \\
& \text { LAE AEMILIVS } \\
& \text { SEVERIANVS } \\
& \text { MIMOGRAPHVS } \\
5 \text { POSVIT }
\end{array}
$$

Deo Tutel lae Aemilius/Severianus/mimographus/ posuit. «Al dios Tutela Emilio Severiano, mimógrafo, lo erigió».

CIL II.4092 = ILS 5276.

2. Ara votiva de Zaragoza dedicada a Genio y Tutela

$$
\begin{array}{cc} 
& \text { GENIO } \\
& \text { TVTELAE } \\
& \text { HORREORVM } \\
& \text { A ANNIVS } \\
5 \text { EVCHARISTVS } \\
& \text { EX VOTO }
\end{array}
$$

Genio/ Tutelae/ horreorum/A(ulus) Annius/ Eucharistus/ ex voto.

«Al Genio, a la Tutela de los almacenes, Aulo Annio Eucharisto de acuerdo con su promesa».

$C I L$ II.2991 = ILS 3667.

3. Ara votiva a Tutela Augusta de Mancha Real (Jaén)

$$
\begin{gathered}
\text { AVGVSTO } \\
\text { PACI PERPETVAE ET CONCORDIAE } \\
\text { AVGVSTAE } \\
\text { VIBIVS FELICIO SEVIR ET } \\
5 \text { VIBIA FELICVLA MINISTRA TVTELAE AVGVSTAE } \\
\text { D S P D D }
\end{gathered}
$$

Augusto/ Paci Perpetuae et Concordiael Augustae/ Vibius Felicio sevir et/ Vibia Felicula ministra Tutelae Augustae/ d(e) s(ua) p(ecunia) d(onum) d(ederunt).

«(Consagrado) a Augusto, a la Paz Perpetua y a la Concordia Augusta, el sevir Vibio Felición y Vibia Felícula, diaconisa de Tutela Augusta, con su propio dinero lo realizaron». 
4. Inscripción a Tutela Augusta (Museo municipal de Tortosa)

TVTELAE AVG
SACRVM
C TERENTIVS ONESIMVS
OB HONOREM SEVIRATVS
5 SVI ET IN HONOREM
C TERENTII VRSI FILI

Tutelae Aug(ustae)/sacrum/C(aius) Terentius Onesimus/ob honorem seviratus/sui et in honorem/ C(aii) Terentii Ursi fili(i).

«Consagrado a Tutela Augusta. Cayo Terencio Onésimo con motivo de su sevirato y en honor de su hijo Cayo Terencio Urso».

CIL II.4056.

5. Inscripción a la diosa Tutela hallada en la provincia de Lugo

$$
\begin{array}{cc} 
& \text { TVTELAE } \\
& \text { L ANTONIVS } \\
\text { AVITVS CVM } \\
\text { FILIS ET ZOSIMA L L } \\
5 \text { EX VOTO }
\end{array}
$$

Tutelae/L(ucius) Antonius/Avitus cum/fili(i)s et Zosima l(iberta)/ ex voto.

«(Consagrado) a Tutela. Lucio Antonio Avito, junto con sus hijos y su (liberta) Zosima, de acuerdo con su promesa».

$$
C I L \text { II. } 2538=I R G \text { II, p. } 149 \text {. }
$$

6. Altar dedicado a Tutela (Chaves, Portugal)

$$
\begin{gathered}
\text { TVTELAE } \\
M \text { AQ LEDA } \\
\text { PEREGRINORVM } \\
\text { EXVP }
\end{gathered}
$$

Tutelae/ $M(. .) A q.(.$.$) Leda/ peregrinorum/ ex v$ (oto) p(osuit).

«A Tutela M..... Aq.... Leda de los peregrinos (extranjeros) lo erigió de acuerdo con su promesa».

CIL II.5618. 
7. Dedicatoria a la diosa Tutela hallada en Arganza (Tineo)

N.Santos, «La inscripción de Arganza (Tineo)...», Lancia 5 (2005) 167ss. = Texto $\mathrm{n}^{\circ} 5$ del Capítulo I de la Segunda Parte

8. Dedicatoria a Fortuna Balnearis

$C I L$ II. $2701=$ Texto $^{\circ} 2$ del Capítulo I de la Segunda Parte

9. Ara dedicada a Tutela Bolgensis

$\begin{array}{ll} & \text { TVTELA } \\ & \text { BOLGENS } \\ & \text { CLAVDIVS } \\ & \text { CAPITO } \\ & \text { PRO S SVA ET } \\ & \text { S P EX VO }\end{array}$

Tutela[e]/Bolgens[i]/Claudius/Capito/pro s(alute) sua et/s(uorum) p(osuit) ex vo(to).

«A la Tutela Bolgense. Claudio Capitón erigió (este monumento) por su salud y la de los suyos de acuerdo con su promesa».

M.A.Rabanal-S.García, Epigrafía romana de León, nº 26.

10. Ara dedicada a Tutela Tiriensis

$\begin{array}{ll} & \text { TVTELAE } \\ & \text { TIRI } \\ & \text { ENSI POMPEI } \\ & \text { CLITIVS } \\ 5 \quad \text { CORINTHV } \\ \text { CALVINVS } \\ \text { EX VOTO }\end{array}$

Tutelae/Tiri/ ensi Pompei(i)/Clitius/Corinthu[s]/Calvinus/ ex voto.

«A la Tutela Tiriense. Clitio, Corintho y Calvino, (esclavos) de Pompeyo, (lo erigieron) de acuerdo con su promesa».

J.M.Blázquez, Religiones primitivas de Hispania, p.63. 